\title{
A Logarithmic Linear Model for Fisheries and Aquaculture Products in EU26
}

\author{
Joel Chiadikobi Nwaubani, Christiana Uzoma Ezechukwu, Adanma Ngozi Ohia, Peace Opara, \\ Uchechi Mgbafor Ezeji, Chinwe Adaugo Uzokwe
}

\begin{abstract}
In fisheries production, aquaculture sector is characterised as a "blue revolution" as it is the fastest developing food industry in the world. Fish farming and aquaculture products are constantly gaining ground than ever before on our daily dishes. Fishes are a great source of affordable protein which the human body needs in regular and specific quantities and also it serves as a major pharmaceutical ingredient such as fish oil soap, body cream and perfume. Moreover, fishes are now being used as raw materials for fillets, canning for eateries and fish feeds. Statisticians and Nutrition/Dietician experts predict that much of the vital protein food necessary to nourish an increasing global population of which pathetically, many are underfed even today will come from marine (saltwater) fisheries. With a total production of 52 million tons in 2017, aquaculture is seen by many as the only solution to replenish the vacuum created in fishes due to an increase in consumption and overfishing. Aquaculture is important because it offers an alternative to overburdening and depleting marine fishery stocks. Currently the depletion rate of European fish stocks is $\mathbf{8 8 \%}$. This study considers the use of a logarithmic linear model to analyse fisheries and aquaculture products in EU26. We consider using data from the European Market Observatory for fisheries and aquaculture, estimated on actual base year from 2006-2017. The analysis of association table (ANOAS) is given to ascertain the percentage of the data which is covered by each model. We investigate and estimate the association model with the best fit and in conclusion, find out that the Row-Column Effects Association Model (RC) of the multivariate model (M=8) has the best fit among all, covering almost $91 \%$ of the total data observed.
\end{abstract}

Index Terms - Association Model, Log-Linear and NonLinear Models, Fisheries and aquaculture products, EU26.

\section{INTRODUCTION}

The European market for seafood is one of the largest in the world. However, compared to the 1980s and 1990s, when there was much growth in aquaculture fisheries, the continuation has not been encouraging. The European Commission has been making efforts to fight this stagnation with its new strategy. The most important countries engaged in the development of aquaculture fisheries as a whole are

Published on November 21, 2020.

Joel Chiadikobi Nwaubani, Advance Higher Education London, UK.

(corresponding e-mail: joelinocool ${ }^{@}$ yahoo.com)

Christiana Uzoma Ezechukwu, Assistant Chief Superintendent, Agricultural Development Programme (ADP), Nigeria.

Adanma Ngozi Ohia, Senior Lecturer, University of Portharcourt, Nigeria

Peace Opara, Confidential Secretary, Abia Secondary Education Management Board (SEMB), Nigeria.

Uchechi Mgbafor Ezeji, Principal 11, Amuzukwu Girls' Secondary School, Nigeria.

Chinwe Adaugo Uzokwe, Lecturer, Michael Okpara University of Agriculture Umudike, Nigeria. those of Asia and Latin America. In the European Union, a country like Greece has the biggest challenge from neighbouring country - Turkey, which, contrary to EU law, subsidises its fish production by 0.60 cents per kilo, which often times creates conditions of unfair competition for Greek fisheries production. Purposely aimed with the program of withdrawal of fishing products, an $80 \%$ of the stocks in the European seas have been fished beyond their maximum sustainable performance.

Consumers' limited information is attributed to their cautious attitude towards fish farming both in terms of health effects and the environment. However, there are regular inspections and if there is any pollution or violation, the damages are paid by the producers themselves which ranges to a loss of many millions of euro. The fish grow in healthy and hygienic conditions and measurements show that at a distance of 50 meters around the cages, there is no adverse effect on the aquatic environment and the seabed.

Fighters (opponents) of fish farming argue or claim that the food which are being used in this production end up in a large proportion of marine resources, thereby, causing them to become entropy and disrupt the stability of the ecosystem. Moreover, to augment their critique they characterise fishes from fish farming and aquaculture as less healthy. Despite the disagreements that exist, most people agree that fish farming and aquaculture ensure jobs in rural and coastal population and enable investment at the local level.

Aquaculture produces know-how (expertise), which is essential for research and development in a country. But the most important of all is the fact that fish farming and aquaculture helps to reduce overfishing.

\section{A. Aquaculture Production in the EU}

Aquaculture refers to the farming of aquatic (freshwater or saltwater) organisms, such as fish, molluscs, crustaceans, and aquatic plants. Aquaculture data are reported in live weight equivalent and value. The EU aquaculture producers have primarily focused on four species namely: mussels (35\%), salmon (15\%), trout (14\%) and oysters (7\%) - with other important farmed species in the EU being sea bream, carp, sea bass and clams. In EU, aquaculture accounts for $20 \%$ of fish production and directly employs some 70.000 people. The sector is mainly composed of Small and Medium-sized enterprises (SMEs) or micro-enterprises in rural and coastal areas. EU aquaculture is renowned for its high quality, sustainability, and consumer protection standards. EU overall output has been more or less constant in volume since 2000 whereas global production at the same time has been growing by nearly $7 \%$ on yearly basis. 


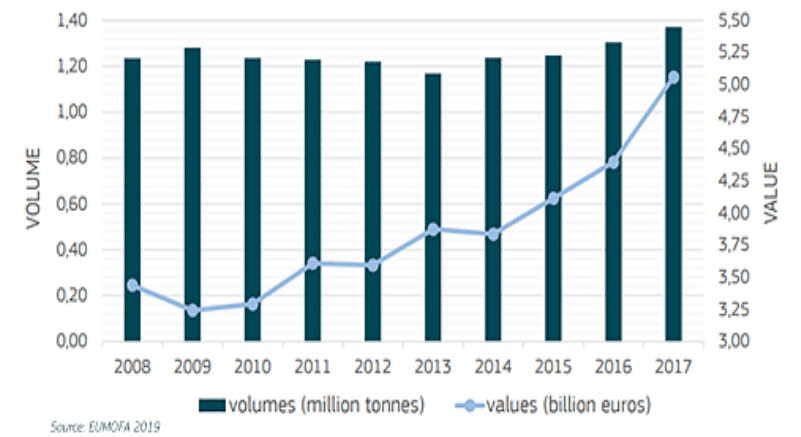

Fig. 1. Aquaculture production in the EU.

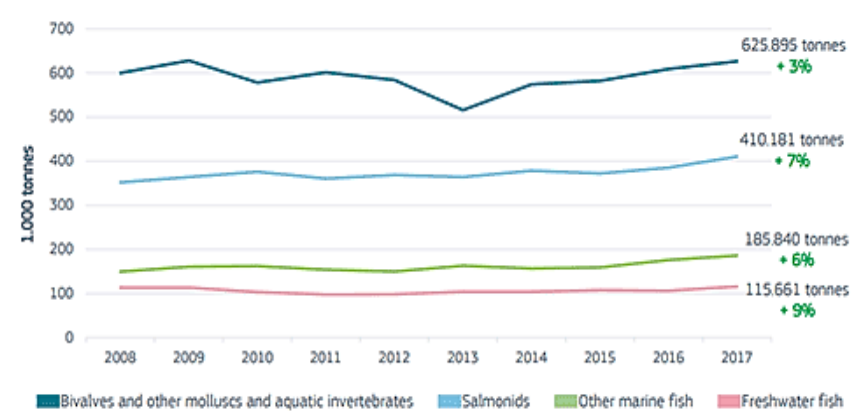

Fig. 2. Volumes of main commodity groups farmed in the EU and \% variations 2017/2016. Source EUMOFA.

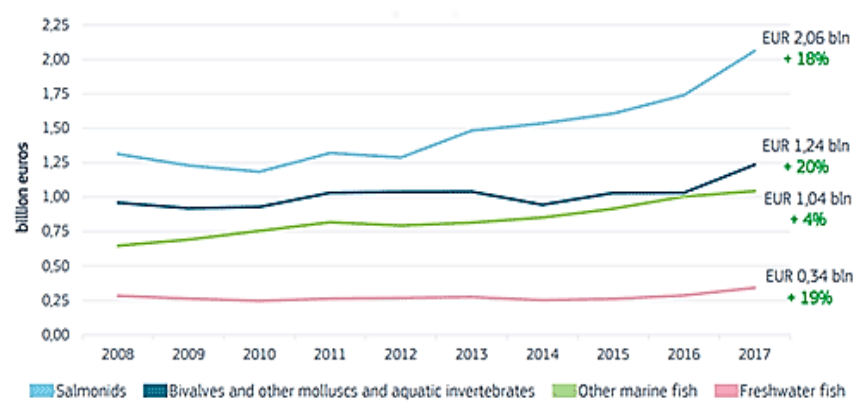

Fig. 3. Values of main commodity groups farmed in the EU and \% variations 2017/2016. Source EUMOFA.

\section{B. Aquaculture Production in Africa Compared to Aquaculture in the EU}

Africa has increased its contribution to global production from 1.2 percent to 2.2 percent in the past decades, though on a minimum scale. However, since 2010 there has been an increase of 39.5 percent as a result of rapid development in freshwater fish farming in sub-Saharan Africa, most notably in Nigeria, Ghana, Kenya, Uganda and Zambia. In West Africa fishing activities, mostly in the marine artisanal subsector, are a major contributor to GDP with high overall contributions in Ghana, Mauritania, and Sierra Leone. In Central Africa, inland fisheries are the major contributor to GDP with high overall contributions by the Democratic Republic of the Congo and Uganda. In Southern Africa, marine industrial fisheries are the major contributor to GDP.

As shown in Table 1, about 1519.64 people were reported as employed in fishery and aquaculture in 2010 with women contributing $8 \%$ of the total workforce. In 2014, 713.04 were reported as engaged in inland fisheries with women constituting a total of $21 \%$. In 2015 , the total fisheries production was estimated at 1027000 tonnes, in which marine catches contributed $36 \%$, inland waters catch embraced $33 \%$ while aquaculture gained $31 \%$. In 2016, a total of 537.90 people was reported to be engaged in other fisheries by $15 \%$ of women. Statistics from Food and Agriculture Organization of the United Nations has shown that Nigeria approximately imports a valued sum of USD 1.2 billion (750.000 tons) and exports USD 284 million annually on fish products from Europe, Latin America, and African countries. Fishery sector contributes to 0.5 percent of national GDP [1].

\begin{tabular}{cccccccc}
\multicolumn{7}{c}{ TABLE 1: FISHERIES STATISTICS OF NIGERIA [1] } \\
\hline $\begin{array}{c}\text { Employment } \\
\text { (thousands) }\end{array}$ & 1980 & 1990 & 2000 & 2010 & 2014 & 2015 & 2016 \\
Aquaculture & $\ldots$ & $\ldots$ & $\ldots$ & 0.01 & $\ldots$ & $\ldots$ & $\ldots$ \\
Capture & 469.07 & 490.00 & 1177.31 & 1519.63 & 1477.65 & 1565.36 & 1190.50 \\
Inland & $\ldots$ & $\ldots 90.00$ & 1177.31 & 1519.64 & 1477.65 & 1565.36 & 1190.50 \\
Marine & 469.07 & 490.00 & 460.69 & 688.08 & 764.62 & 782.61 & 537.90 \\
\hline
\end{tabular}

The contribution of a sector to national Gross Domestic Product (GDP) is a key macroeconomic indicator frequently referred to by decision-makers when highlighting a particular sector's importance for a national economy. Information on the contribution of a natural-resource sector to GDP is useful as one of many indicators, not only to monitor the progress of sustainable resource management, but also serves as key for effective monetary policy-making. Although, often not fully recognised as a major productive activity in many African countries, the contribution of fishery and aquaculture production to national economies could not be overemphasised. In addition, the supply of food from fishery products contributes to GDP, which in turn provides income for fish farmers and processors, will give a further boost to the government revenues through fisheries taxes. Fisheries in Africa are characterised by small-scale fisheries contributing greatly to employment. However, while fishing itself is clearly a vital source of employment, a previous study by the World Bank highlighted that the bulk of fisheries employment is in the post-harvest economic activities, which includes fish processing and marketing [2].

\section{AbleKristal Farms}

For many Nigerian farmers like AbleKristal Farms, fishery and aquaculture is an opportunity. Everyone has the power to influence what is produced through healthy food choices, which also contributes to more sustainable food systems. Fish farming involves raising fish in tanks or enclosures, usually for private or commercial purpose. The most common fish species raised by fish farmers in Nigeria are: Carp, tilapia, and catfish. AbleKristal Farms which is located in Umunkaru Umuawa-Alocha, Umuahia north of 
Abia state, Nigeria mainly deals in Catfish, Tilapia, Feeds, Poultry, Agro-Allied Products, Pond Construction and Consultancy Services. AbleKristal global venture which is owned and managed by Mr Abel Ogbonna Ezechukwu and Mrs Christiana Uzoma Ezechukwu is helping to make fish farms more productive so that they can feed more Abians and Nigerians in general. Due to the fact that there isn't constant electricity supply in the rural and urban areas in Nigeria, innovations like charcoal dryers are being used for 'Smoke Fish' products which extend the shelf-life of one of Nigeria's staple foods, while fish farming is becoming more profitable. This method makes it more advantageous than capture fisheries based on the fact that you have the control in determining what kind of fish you want to farm, the quantity, location of farm feed and the treatment of the fishes at all times. Fishery and aquaculture production just like every other business ensures high levels of tenacity, commitment, adaptability, reliability, and special skills.

Based on the natural conditions in Nigeria, it is worth saying that there are basic conditions required for fishery and aquaculture in Nigeria. However, if Nigerians could use their scarce means for alternative uses according to circumstances that persist and raise fish with scientific methods, fish products in Nigeria market will be more efficient and effective in quantity and quality.

According to United Nations data, Nigeria's strongly growing population in 2017 was 190.873 .246 million and its very high demand for fish positioned the country on a much more strongly market driven path based on commercial production as a result of rapid development in rural and urban areas. With capital investment, selection of the hardy catfish for farming, development of intensively good management of fish hatcheries and use of high quality fish feeds, farmers were able to establish a new model for raising fish in concrete tanks or natural pond in their courtyard, thus, minimising poaching (illegal hunt or catch fish on land that is not one's own or in contravention of official protection) and allow farmers to reap the rewards of their labour and perseverance. Unarguably, the Nigerian government is not doing much as expected to expand fishery and aquaculture scale and maximise annual production in order to meet domestic market demand [3].

\section{Artisanal Fisheries}

Artisanal fisheries constitute the most significant fishery sector in terms of people who engage in it. This sector, accounts for the majority of a country's fish production. However, this sector is the poorest in terms of its standard of living, with the fishermen generally making a sustainable living.

Capture fisheries which are equivalent to hunting in forests, involves hunting for fishes in their natural habitats along the coastline and the boundary of inland water, such as: dams, lakes, rivers, lagoon, etc. By hunting on land, fishermen make use of small-medium sized canoe and make basic tools like traps, nets, and hooks to catch fishes.

\section{E. Macroeconomic Context}

a) Marine Fuel \{(Average price of marine diesel in Italy, France, Spain, and the UK (Euro/Litre)\}

In 2017, the fuel price in the French ports of Lorient and
Boulogne was 0.44 EUR/litre and increased 5\% compared with October 2017. Compared with 2016, it was 7\% higher. In the Italian ports of Ancona and Livorno, the average price of marine fuel in 2017 was $0.45 \mathrm{EUR} /$ litre. It increased 5\% over the previous month and $10 \%$ over 2016 . The price of marine fuel in the ports of A Coruña and Vigo, Spain reached an average of 0.44 EUR/litre in 2017 and increased $5 \%$ over 2017 and $13 \%$ over 2016. The fuel price observed in the UK ports of Grimsby and Aberdeen was 0.42 EUR/litre and increased $5 \%$ over the previous month. Compared with the same month a year ago, the fuel price increased $8 \%$.

\section{b) Food and Fish Prices}

In October 2017, annual EU inflation was 1.7\%, down from $1.8 \%$ in September 2017. A year earlier, the rate was $0.5 \%$. In October 2017, the lowest annual rates were recorded in Cyprus $(+0.4 \%)$, Ireland, Greece and Finland (all $+0.8 \%)$, while the highest annual rates were registered in Lithuania $(+4.2 \%)$, Estonia $(+4.0 \%)$, and the UK $(+3.0 \%)$. Compared with September 2017, annual inflation rose in 9 Member States, remained stable in five (Croatia, Luxembourg, Poland, Slovakia and the UK), and fell in fourteen (Belgium, Denmark, Germany, Greece, Spain, Italy, Latvia, Lithuania, Hungary, Austria, Slovenia, Finland, Sweden, and the Netherlands). In October 2017, prices of food and non-alcoholic beverages increased $0.7 \%$, while prices of fish and seafood decreased $0.4 \%$, compared with September 2017. Compared with October 2016, both food and fish prices increased $2.9 \%$ and $3.3 \%$, respectively. Compared with October 2015, fish and seafood prices increased $6.7 \%$, while food and non-alcoholic beverages increased $2.7 \%$.

\section{F. Challenges Facing Fishery and Aquaculture in African Countries}

Surrounded by water from all directions, Africa is a continent with clearly defined borders. In the north it is separated from Europe by the Mediterranean Sea, in the northeast, is separated from Asia by the Suez Canal and farther by the Red Sea. From the east and southeast, it is surrounded by the Indian Ocean, from the west by the Atlantic Ocean. The total number of independent states in Africa is 54. The transcontinental country in this region is Egypt, also having a small part of its territory in Asia, on the other side of the Suez Canal, but politically it is a member of the African Union.

Among the African countries, the biggest one is Algeria, occupying around $7 \%$ of the continent's territory. And the smallest nation is Seychelles, the worldwide famous luxurious beach holiday destination, occupying 115 islands stretching along the mainland's eastern coast. Morocco is in the first place among the most popular travel spots in Africa, the second place belongs to South Africa, followed by Egypt and Tunisia [4].

Nigeria, one of the leading African countries is located in the West of Africa, whose land area is 923.768 square kilometres (356.669 sq. mi) is bordering Niger in the north, Chad in the northeast, Cameroon in the east and Benin Republic in the west. Coastal areas receive more rain every year while annual rainfall in the eastern region is $4318 \mathrm{~mm}$, western region is $1778 \mathrm{~mm}$, central region records $1270 \mathrm{~mm}$ 
and northern region records only $508 \mathrm{~mm}$.

Most African countries in the sub-Saharan Africa, most notably Nigeria, Ghana, Kenya, Uganda, and Zambia have been confronted with many challenges in fishery and aquaculture such as:

$>$ Lack of capital which hinders the necessary variety improvement and as a result, fish farmers cannot be able to supply high-yield breeding varieties.

$>$ The high cost of operations

$>$ The high cost of spare parts of fishery and aquatic facilities as there are no provisions for assistance from the government.

$>$ Fish firms have to operate their own cold room run on generators due to unavailability or unreliability of power systems, thereby operating at a very high cost on daily purchase of petrol or diesel.

\section{G. African Fishery and Aquaculture Development}

African government, through its agencies, continues to be the major source of funds for aquaculture research and development. Despite the numerous agricultural, commercial, merchant, and industrial banks in the African countries, access by aquaculturists to institutional credit remains a problem. Aquaculture has been a matter of less importance in the successive government's plans and budgets in African countries and on a state platform.

In Nigeria it's worth saying that the existence of the Land Use Decree of 1978 was transformed into an Act in 1982, and its negative effect on land acquisition for aquaculture. This Land Act provides land ownership on the state, and the state governor has statutory power to revoke common occupation rights if it is in the general public interest. The negotiation process to secure land tenure rights is timeconsuming and corruption-ridden, especially for large scale fishery and aquaculture farms. By virtue, there is a need to replace what has hitherto been a haphazard method of easy access to land to any other form of agriculture.

\section{STATISTICAL DATA AND PROCESSING OF THE RESULTS}

The data used in this study was obtained from the European Market Observatory for fisheries and aquaculture (EUMOFA), calculated on an annual basis. The processing of observations (data) consists of Fisheries and Aquaculture products in EU26. Below in table 2 are the lists of data under our study for the subsequent years (2006-2017).

TABLE 2: SHOWING FISHERIES AND AQUACULTURE PRODUCTS (IN TONNES) IN EU26 [5]

\begin{tabular}{|c|c|c|c|c|c|c|c|c|c|c|c|c|}
\hline GEO/TIME & 2006 & 2007 & 2008 & 2009 & 2010 & 2011 & 2012 & 2013 & 2014 & 2015 & 2016 & 2017 \\
\hline Belgium & 95 & 85 & 85 & 160 & 187 & 183 & 183 & 126 & 74 & 41 & 13 & 13 \\
\hline Bulgaria & 473 & 544 & 425 & 778 & 365 & 294 & 231 & 447 & 249 & 315 & 326 & 443 \\
\hline Czech Republic & 1820 & 1756 & 1723 & 1878 & 1948 & 2010 & 1921 & 1967 & 1938 & 2046 & 2043 & 2045 \\
\hline Denmark & 4192 & 3970 & 4237 & 4267 & 4361 & 4157 & 3203 & 3777 & 4281 & 3901 & 2791 & 3117 \\
\hline Germany & 8324 & 6543 & 7302 & 7957 & 6589 & 5341 & 4985 & 7428 & 5723 & 4469 & 3768 & 4500 \\
\hline Estonia & 27 & 26 & 26 & 20 & 23 & 47 & 26 & 37 & 25 & 56 & 70 & 78 \\
\hline Ireland & 3493 & 3685 & 4238 & 4386 & 5125 & 6094 & 6257 & 6252 & 5836 & 6005 & 5312 & 5250 \\
\hline Greece & 3985 & 4884 & 5993 & 8427 & 9542 & 9751 & 8793 & 10143 & 9714 & 10627 & 11317 & 11319 \\
\hline Spain & 23163 & 23917 & 31370 & 31819 & 30904 & 30892 & 25473 & 26820 & 29332 & 21937 & 29489 & 28498 \\
\hline France & 28553 & 28724 & 26785 & 26486 & 26680 & 25166 & 25177 & 23962 & 24267 & 24516 & 23761 & 23745 \\
\hline Italy & 18937 & 19572 & 20863 & 21037 & 21653 & 21833 & 18429 & 19188 & 11822 & 18110 & 17358 & 18099 \\
\hline Cyprus & 79 & 97 & 118 & 142 & 188 & 188 & 186 & 182 & 218 & 239 & 361 & 320 \\
\hline Latvia & 38 & 35 & 43 & 47 & 33 & 46 & 43 & 64 & 55 & 54 & 57 & 73 \\
\hline Lithuania & 154 & 152 & 152 & 165 & 200 & 200 & 175 & 236 & 270 & 201 & 223 & 338 \\
\hline Hungary & 808 & 933 & 1022 & 1195 & 1289 & 1306 & 1157 & 1187 & 1274 & 1366 & 1469 & 1592 \\
\hline Malta & 155 & 180 & 195 & 200 & 175 & 124 & 112 & 89 & 87 & 74 & 717 & 859 \\
\hline Netherlands & 9987 & 9821 & 12009 & 10876 & 7523 & 5704 & 5443 & 6654 & 7860 & 7137 & 4220 & 5337 \\
\hline Austria & 295 & 302 & 291 & 307 & 285 & 239 & 233 & 223 & 227 & 242 & 250 & 254 \\
\hline Poland & 2770 & 2868 & 2979 & 3371 & 3580 & 3546 & 3271 & 3544 & 3513 & 3792 & 3587 & 3689 \\
\hline Portugal & 536 & 719 & 754 & 627 & 754 & 821 & 829 & 803 & 670 & 670 & 790 & 747 \\
\hline Romania & 1390 & 1117 & 961 & 900 & 973 & 1082 & 925 & 904 & 814 & 728 & 911 & 1031 \\
\hline Slovenia & 87 & 92 & 91 & 121 & 118 & 126 & 129 & 135 & 157 & 135 & 137 & 135 \\
\hline Slovakia & 95 & 125 & 65 & 87 & 89 & 100 & 83 & 88 & 118 & 96 & 126 & 120 \\
\hline Finland & 1766 & 1643 & 1602 & 1545 & 1540 & 1574 & 1513 & 1256 & 1282 & 1436 & 1289 & 1303 \\
\hline Sweden & 824 & 668 & 548 & 600 & 483 & 677 & 562 & 633 & 599 & 588 & 755 & 537 \\
\hline $\begin{array}{c}\text { United } \\
\text { Kingdom }\end{array}$ & 10990 & 12972 & 13742 & 15480 & 15249 & 17052 & 17904 & 18184 & 20720 & 17281 & 17185 & 17420 \\
\hline
\end{tabular}

With the help of the Categorical Data Analysis program (CDAS), we were able to ascertain the results of our data for Fisheries and Aquaculture products in EU26, estimated on actual base year from 2006-2017. Table 2 above show the volumes, values and prices of fisheries and aquaculture products of all the models to be estimated. The statistics used to compare and contrast the association (correlation) of the models are $\mathrm{X}^{2}$ (Pearson) Chi - Square and the Likelihood-Ratio Chi - Square $\mathrm{G}^{2}$-probability ratio [6]. In continuation, the following results are shown below:

\section{A. Null Association-Independence Model (O)}

The analysis using the independence model has the following results:

TABLE 3: THE INDEPENDENCE MODEL

\begin{tabular}{lc}
\hline Pearson chi-square & 332746.22956 \\
Likelihood-ratio chi-square & 309659.39951 \\
Degrees of freedom & 275 \\
Index of dissimilarity & 0.16244 \\
Final iteration & 3 \\
Maximum deviation & 0.00 \\
\hline
\end{tabular}




\section{B. Uniform Association Model (U)}

The analysis using the model of uniformity has the following results:

\begin{tabular}{lc}
\multicolumn{2}{c}{ TABLE 4: THE UNIFORM MODEL } \\
\hline Pearson chi-square & 208471.26698 \\
Likelihood-ratio chi-square & 214019.18509 \\
Degrees of freedom & 274 \\
Index of dissimilarity & 0.12955 \\
Final iteration & 12 \\
Maximum deviation & 0.00036294 \\
\hline
\end{tabular}

\section{Row-Effects Association Model(R)}

The analysis using the row-effects model gives the following results:

\begin{tabular}{lc}
\multicolumn{2}{c}{ TABLE 5: THE ROW-EFFECTS MODEL } \\
\hline Pearson chi-square & 164211.97186 \\
Likelihood-ratio chi square & 174101.19092 \\
Degrees of freedom & 250 \\
Index of dissimilarity & 0.11428 \\
Final iteration & 15 \\
Maximum deviation & 0.00095094 \\
\hline
\end{tabular}

\section{Column-Effects Association Model (C)}

The analysis using the columns-effects model of our have the following results:

TABLE 6: THE COLUMNS-EFFECTS MODEL

\begin{tabular}{lc}
\hline Pearson chi-square & 77484.70225 \\
Likelihood-ratio chi-square & 77101.44234 \\
Degrees of freedom & 264 \\
Index of dissimilarity & 0.06840 \\
Final iteration & 18 \\
Maximum deviation & 0.00045139 \\
\hline
\end{tabular}

\section{E. Row-Column Effects Association Model I $(R+C)$}

The analysis using the model of the column-effects in an additive method and have the following results:

\begin{tabular}{lc} 
TABLE 7: THE COLUMN-EFFECTS IN AN ADDITIVE METHOD \\
\hline Pearson chi-square & 46641.57876 \\
Likelihood-ratio chi-square & 45805.28468 \\
Degrees of freedom & 240 \\
Index of dissimilarity & 0.05407 \\
Final iteration & 17 \\
Maximum deviation & 0.00034113 \\
\hline
\end{tabular}

\section{F. Row-Column Effects Association Model II (RC)}

The analysis using the model of the column-effects in a multiplicative method show the following results:

\begin{tabular}{cc} 
TABLE 8: THE COLUMN-EFFECTS IN A MULTIPLICATIVE METHOD \\
\hline Pearson chi-square & 27544.46188 \\
Likelihood-ratio chi-square & 27608.77251 \\
Degrees of freedom & 240 \\
Index of dissimilarity & 0.03980 \\
Final iteration & 17 \\
Maximum Deviation & 0.00099269 \\
\hline
\end{tabular}

\section{ASSOCIATION MODEL}

In the categorical data analysis system, we apply the methodology by considering six of the most commonly used association models. These are:

1. The model of Independence or null association model which is also symbolized by $(\mathrm{O})$ and holds that there is no relationship between the variables. The log-linear model is:

$$
\log \left(\mathrm{F}_{\mathrm{ij}}\right)=\lambda+\lambda_{\mathrm{A}(\mathrm{i})}+\lambda_{\mathrm{B}(\mathrm{j})}
$$

where $\log$ denotes the natural logarithm, $F_{i j}$ the expected frequencies under the independence model, $\lambda_{\mathrm{A}(\mathrm{i})}$ are the rows main effect and $\lambda \mathrm{B}_{(\mathrm{j})}$ are the columns main effect [7].

2. The Uniform association model, which is symbolized by $(\mathrm{U})$ in log-linear form is:

$$
\log \left(\mathrm{F}_{\mathrm{ij}}\right)=\lambda+\lambda_{\mathrm{A}(\mathrm{i})}+\lambda_{\mathrm{B}(\mathrm{j})}+\varphi \chi_{\mathrm{i}} \mathrm{y}_{\mathrm{j}}
$$

where $\varphi$ is a single parameter for interaction and $\chi_{i}, y_{j}$ are the scores for the row and column variables $(i=1, \ldots, I, j$ $=1, \ldots, \mathrm{J})$ respectively.

3. The row effects model (R) where linear-by-linear interaction holds that

$$
\log \left(\mathrm{F}_{\mathrm{ij}}\right)=\lambda+\lambda_{\mathrm{A}(\mathrm{i})}+\lambda_{\mathrm{B}(\mathrm{j})}+\varphi \mu_{\mathrm{I}} \mathrm{y}_{\mathrm{j}}[16]
$$

where $y_{j}$ are fixed scores for the column variable $(j=1, \ldots, J)$ and $\mu_{\mathrm{I}}$ are unknown scores for the row variable $(i=1, \ldots, I)$.

4. The column effects model (C) is the same as the $\mathrm{R}$ model with a change in subscripts:

$$
\log \left(\mathrm{F}_{\mathrm{ij}}\right)=\lambda+\lambda_{\mathrm{A}(\mathrm{i})}+\lambda_{\mathrm{B}(\mathrm{j})}+\varphi v_{\mathrm{j}} \mathrm{x}_{\mathrm{I}},
$$

where $\mathrm{x}_{\mathrm{I}}$ are fixed scores for the row variable $(\mathrm{i}=1, \ldots, \mathrm{I})$ and $v_{\mathrm{j}}$ are unknown scores for the column variable $(\mathrm{j}=1, \ldots, \mathrm{J})$.

5. The model that allows both row and column effects in additive form is called the $\mathrm{R}+\mathrm{C}$ model [8]. The logfrequency version of the above model is:

$\log \left(F_{i j}\right)=\lambda+\lambda_{\mathrm{A}(i)}+\lambda_{\mathrm{B}(j)}+\sum_{K=1}^{I-1} \beta_{K} y_{j} Z_{A(K)}+\sum_{K=1}^{J-1} Y_{K} x_{i} Z_{B(K)}$

where $\chi_{\mathrm{i}}, \mathrm{y}_{\mathrm{j}}$ are the scores (as defined earlier), $Z_{A(i)}$ and $Z_{B(j)}$ denote to variables (dummy variables) for the row and column levels respectively.

6. The model, instead of additive row and column effects on the local odds ratios, has multiplicative effects called the $\mathrm{R} * \mathrm{C}$ model or model II [9]. The log-multiplicative model is:

$$
\log \left(\mathrm{F}_{\mathrm{ij}}\right)=\lambda+\lambda_{\mathrm{A}(\mathrm{i})}+\lambda_{\mathrm{B}(\mathrm{j})}+\varphi \mu_{\mathrm{I}} v_{\mathrm{j}}
$$

where the row score parameters $\mu_{\mathrm{I}}$ and column score parameters $v_{\mathrm{j}}$ are not known but are estimated in the data.

Our goal is to find out the model that has the best fit among the 6 models which we are examining, i.e., the production of aquaculture fishing products (in tonnes) in EU26 for the period 2006-2017. For this reason, we are going to first examine the Index of Dissimilarity (L2), which shows that, the lesser the number, the more our model will give the best fit to match the data under consideration.

We analyse the six association model describe above, with the help of the categorical data analysis statistical programme [10]. We used the Pearson chi-squared $\left(\mathrm{X}^{2}\right)$ statistics, the likelihood-ratio chi-square $\left(\mathrm{G}^{2}\right)$ statistics and the index of dissimilarity which is equated by:

$$
D=\sum_{I j}\left|f_{i j} / n-F_{i j} / n\right| / 2
$$


where $f_{i j}$ are the observed frequencies and $F_{i j}$ are the expected frequencies (under the model).

Additionally, we have the following results as shown in the table below:

\begin{tabular}{lc}
\multicolumn{2}{c}{ TABLE 9: INDEX OF DISSIMILARITY } \\
\hline Null Association-Independence Model (O) & 0.16244 \\
Uniform Association Model (U) & 0.12955 \\
Row-Effects Association Model (R) & 0.11428 \\
Column-Effects Association Model (C) & 0.06840 \\
Row+Columns Effects Association Model & 0.05407 \\
(R+C) & \\
Row Column Effects Association Model & 0.03980 \\
\hline
\end{tabular}

In Table 9 above, it seems at first sight that the Row Column Effects of the Association Model $\left(\mathrm{R}^{*} \mathrm{C}\right)$ adjusted better to the percentage of the production of fisheries products (in tonnes) in EU26 for the period 2006-2017 for the years under study (having the lowest index of dissimilarity) with $\mathrm{D}=0.03980$.

Since we have models with similar lower ratio, we justify the model with the best fit to match both counties and years by calculating the Index BIC (Bayesian information criterion). In statistics, the Bayesian information criterion (BIC) or Schwarz criterion is a criterion for model selection among a finite set of models; the model with the lowest BIC is preferred. It is based, in part, on the likelihood function. When fitting models, it is possible to increase the likelihood by adding parameters but doing so may result in over-fitting. BIC attempt to resolve this problem by introducing a penalty term for the number of parameters in the model and gives the best solution [11].

The formula for this calculation is:

$$
B I C=G^{2}-(D . F .) \log (n)
$$

Notations:

$\mathrm{G}^{2}=$ the likelihood-ratio chi-square statistics.

d.f. $=$ degrees of freedom of the models.

$\mathrm{n}=$ the size of our sample $(1807901.0000)$.

$\log (n)=\log (1790717.6000)=14.4077$

When comparing a number of models, the model with the smallest index of BIC is assumed to be the best. So, we choose the models that have similar and lowest INDEX OF DISSIMILARITY out of the six models. More precisely, we will consider the $4^{\text {th }}, 5^{\text {th }}$ and $6^{\text {th }}$ models respectively. Subsequently, the calculation is as follows:

$$
\begin{gathered}
4^{\text {th }} \text { model: } \mathrm{BIC}=\mathrm{G}^{2}-(\mathrm{d} . \mathrm{f}) \log (\mathrm{n})=0.80136-(264 \times \\
14.4077)=73298.8095 \\
5^{\text {th }} \text { model: } \mathrm{BIC}=\mathrm{G}^{2}-(\mathrm{d} . \mathrm{f}) \log (\mathrm{n})=45805.28468- \\
(240 \times 14.4077)=42347.59434 \\
6^{\text {th }} \text { model: } \mathrm{BIC}=\mathrm{G}^{2}-(\text { d.f }) \log (\mathrm{n})=27608.77251- \\
(240 \times 14.4077)=24150.92451
\end{gathered}
$$

From the above calculations, it could be observed that the 6th model - Row Column Effects Association Model (RC) finally accounts for the best fit from the results because it has the smallest index of BIC.

\section{A. Analysis of Association Model}

In continuation, the association model passes through several tests to ascertain the accuracy, quality, or satisfactory fit of each model. Tests are done through the use of the likelihood-ratio chi-square $\left(\mathrm{G}^{2}\right)$ statistics and the Pearson chi-squared $\left(\mathrm{X}^{2}\right)$ distribution. In the case of the $\mathrm{X}^{2}$ distribution, the Statgraph programme will be of good help.

Initially, we observe that the likelihood-ratio chi-square statistic for the Independence model (O) which is $\mathrm{G}^{2}=520884.36900$ with 275 degrees of freedom. The $95 \%$ reference point chi-square distribution is 315.233 . It has unacceptable fit because the $\mathrm{X}^{2}$ distribution is $<\mathrm{G}^{2}$.

Subsequently, the Uniform association model has $\mathrm{G}^{2}=465436.18993$ with 274 degrees of freedom. The $95 \%$ reference point chi-square distribution is 314.158. As it could be noticed, this statistic is not accepted and does not have a satisfactory fit since the $X^{2}$ distribution is $<G^{2}$.

Moreover, the statistic $G^{2}$ for the Row model $(R)$ is reduced dramatically for 348506.13881 with 250 degrees of freedom. The $95 \%$ reference point chi-square distribution is 288.315. The row model is also not accepted because the $\mathrm{X}^{2}$ distribution is $<\mathrm{G}^{2}$.

The Column model (C) has $\mathrm{G}^{2}=275030.86927$ with 264 degrees of freedom. The $95 \%$ reference point chi-square distribution is 303.398 which show even the worst fit as we could observe that the $\mathrm{X}^{2}$ distribution is $<\mathrm{G}^{2}$.

The statistics of the model $\mathrm{R}+\mathrm{C}$, that considers the effects for both Countries and Years in additive form, is $\mathrm{G}^{2}=164882.12076$ with 240 degrees of freedom. The $95 \%$ reference point chi-square distribution is 277.528 has equally unacceptable fit since the $\mathrm{X}^{2}$ distribution is $<\mathrm{G}^{2}$.

Finally, the model RC, that is log multiplicative but not log-linear, the $\mathrm{G}^{2}$ Statistics is 42921.51701 with 240 degrees of freedom. The $95 \%$ reference point chi-square distribution is 277.528. Furthermore, the statistics is dramatically reduced just as the previous model because they have identical degrees of freedom but is shown to remain unacceptable fit because the $\mathrm{X}^{2}$ distribution is $<\mathrm{G}^{2}$.

By virtue of the index of dissimilarity of the models as mentioned earlier, the model RC has the best fit. However, upon clear test to ascertain the accuracy, quality, or satisfactory fit of the model, we find out that it has a very poor fitting, making it unacceptable [12], [13].

Consequently, we have to find out the degree or level of effects on each model. To verify this, we will construct the analysis of association (ANOAS) Table.

\section{B. Analysis of Association Table (ANOAS)}

The ANOAS table in table 10 below was given by [14]. In this table, the $\mathrm{X}^{2}$ is divided so that it can be used as two factor analysis of variance by making use of the $G^{2}(0)$ statistics for the base (zero) independence model which measures the total deviation of the variables. In other words, we can find the percentage of the baseline chi-squared $\mathrm{X}^{2}$ distribution, which have effects on each of the models on the phenomenon being studied. 
TABLE 10: ANOAS

\begin{tabular}{cccc}
\hline Models & Likelihood-G & DF & $\begin{array}{c}\text { Index of } \\
\text { Dissimilarity }\end{array}$ \\
\hline O & 309659,39951 & 275 & 0.16244 \\
U & 214019.18509 & 274 & 0.12955 \\
R & 174101.19092 & 250 & 0.11428 \\
C & 77101.44234 & 264 & 0.06840 \\
R+C & 45805.28468 & 240 & 0.05407 \\
RC & 27608.77251 & 240 & 0.03980 \\
\hline
\end{tabular}

The analysis of association table (ANOAS) has the following differences of our models: $\mathrm{O}-\mathrm{U}$ is the overall or total effects of the models, U-C are the column effects model, $\mathrm{C}-\mathrm{CR}$ are the column effects model which gives the effects of the column RC and the residuals of the models.

TABLE 11: ANOAS MODEL UNIFORMITY

\begin{tabular}{|c|c|c|c|}
\hline Models & $\mathrm{G}^{2}$ Values & D.F. & $\mathrm{P} \%)$ \\
\hline 1. General Effects (O-U) & 95640.2145 & 1 & $30.89 \%$ \\
\hline 2. Rows Effects (U-C) & 136917.7427 & 24 & $47.31 \%$ \\
\hline $\begin{array}{l}\text { 3. Column-effects which } \\
\text { gives the Row- } \\
\text { effects (C-RC) }\end{array}$ & 49492.66983 & 24 & $15.98 \%$ \\
\hline 4. Residual (RC) & 27608.77251 & 240 & $5.82 \%$ \\
\hline Total $(\mathrm{O})$ & 309659.39951 & 275 & $100.00 \%$ \\
\hline
\end{tabular}

From the ANOAS table we created, the uniform association model (U) as shown in table 11 above, covers $30.89 \%$ of the total baseline chi-squared $\mathrm{X}^{2}$ distribution, the Row model (R) accounts for a large percentage of $47.31 . \%$, the Column-effects which gives the Row-effects (C-RC) covers a small percentage of $15.98 \%$ of the baseline chisquared value. Finally, the row column effects (Residuals) are weaker because the RC model accounts for only $5.82 \%$ of the baseline chi-squared value.

We could therefore observe that at the rate of $5.82 \%$, the variation which is attributed to the null-independence has been measured from the model of RC. This rate is quite satisfactory and we can say that the corresponding percentage of population change in 25 countries of the European Union (Belgium, Bulgaria, Czech Republic, Denmark, Germany, Estonia, Ireland, Greece, Spain, France, Italy, Cyprus, Latvia, Lithuania, Hungary, Malta, Netherlands, Austria, Poland, Portugal, Romania, Slovenia, Slovakia, Finland, Sweden and United Kingdom), as shown from the data depended slightly positive on the association of both the countries and also from the years under our study (2006-2017).

We could as well say that the percentage of $(309659.39951-27608.77251) / 309659.39951=91 \%$ of the data is explained by the column effects model (on the local odds ratios in a multiplicative way), thus, giving it a satisfactory fit but unacceptable due to its poor fit as was earlier found in our study, i.e. the value of the Pearson chisquared $\mathrm{X}^{2}$ distribution for the $95 \%$ reference point are bigger than the model (RC).

Furthermore, because our best model (RC) under our study is unacceptable as a result of its bad fit based on the index BIC, upon clear examination to test the accuracy, quality or satisfactory fit of the model, therefore, we'll proceed to examining the multivariate model to find the model with a satisfactory fit.

\section{The Multivariate Models}

In the RC (M) association model, $\mathrm{M}$ represents the dimension fit to be, which is utilized by the row-column dimension (RCDIM PROGRAM). As shown in table 12 below the multivariate model $\mathrm{RC}(\mathrm{M}=8)$ is the acceptable model with the best fit (having the $\mathrm{X}^{2}>\mathrm{G}^{2}$ and it also has the lowest degree of freedom [12].

Model RC (4) multivariate row, column, $M=4$

Model RC (5) multivariate row, column, $\mathrm{M}=5$

Model RC (6) multivariate row, column, $M=6$

Model RC (7) multivariate row, column, $M=7$

Model RC (8) multivariate row, column, $\mathrm{M}=8$

TABLE 12: THE MULTIVARIATE MODEL

\begin{tabular}{cccccc}
\hline Model & $\mathbf{R C}(\mathbf{4})$ & $\mathbf{R C}(\mathbf{5})$ & $\mathbf{R C}(\mathbf{6})$ & $\mathbf{R C}(\mathbf{7})$ & $\mathbf{R C}(\mathbf{8})$ \\
\hline $\mathbf{X}^{\mathbf{2}}$ & 5183.00041 & 2905.09828 & 1328.76963 & 492.57615 & 282.82138 \\
$\mathbf{G}^{\mathbf{2}}$ & 5170.48767 & 2914.45914 & 1337.01587 & 490.17592 & 280.65305 \\
D.F. & 147 & 120 & 95 & 72 & 51 \\
$\mathbf{D}$ & 0.01771 & 0.01104 & 0.00636 & 0.00340 & 0.00245 \\
\hline
\end{tabular}

\section{A. Examination of the Multivariate Model}

In the RC (M) association model, $\mathrm{M}$ represents the dimension to be fit, which is utilized by PROG RCDIM. As it is shown in table 12 above the multivariate model RC $(\mathrm{M}=8)$ is the acceptable model with the best fit.

The multivariate model RC (4) with $\mathrm{M}=4$ has likelihoodratio chi-square statistic $\mathrm{G}^{2}=5170.48767$ with 147 degrees of freedom (d.f.). Thus, we find out that the $95 \%$ reference point of the $\mathrm{X}^{2}$ distribution is 5183.00041. It has a bad fit. We could conclude therefore that this model has a bad fit because the $\mathrm{X}^{2}$ distribution is much smaller than the likelihood-ratio chi-square statistic $\mathrm{G}^{2}$.

Moreover, the multivariate model RC (5) with $M=5$ has likelihood-ratio chi-square statistic $\mathrm{G}^{2}=2914.45914$ with 120 degrees of freedom (d.f.). The 95th percentile of the reference chi-square distribution is 2905.09828. Similarly, this model has a bad fit since the $\mathrm{X}^{2}$ distribution is much smaller than the likelihood-ratio chi-square statistic $\mathrm{G}^{2}$.

The multivariate model RC (6) with $\mathrm{M}=6$, has likelihoodratio chi-square statistic $\mathrm{G}^{2}=1337.01587$ with 95 degrees of freedom (d.f.). Thus, we find out that the $95 \%$ reference point of the $\mathrm{X}^{2}$ distribution is 1328.76963 . It has a very bad fit, thus, making it unacceptable.

The multivariate model RC (7) with $\mathrm{M}=7$, has likelihoodratio chi-square statistic $\mathrm{G}^{2}=490.17592$ with 72 degrees of freedom (d.f.). Thus, we find out that the $95 \%$ reference point of the $X^{2}$ distribution is 492.57615 . Here we could see that the multivariable $\mathrm{RC}$ model with $\mathrm{M}=$ has a satisfactory fit since the $95 \%$ reference point of the $\mathrm{X}^{2}$ distribution is greater than the likelihood-ratio chi-square statistic $\mathrm{G}^{2}$.

Finally, the multivariate model $\mathrm{RC}(8)$ with $\mathrm{M}=8$, has 
likelihood-ratio chi-square statistic $\mathrm{G}^{2}=280.65305$ with 51 degrees of freedom (d.f.). The $95 \%$ reference point of the $\mathrm{X}^{2}$ distribution is 282.82138 . The multivariable RC model with $\mathrm{M}=8$ has the best fit and with the lowest degree of freedom since the $95 \%$ reference point of the $\mathrm{X}^{2}$ distribution is greater than the likelihood-ratio chi-square statistic $\mathrm{G}^{2}$. We equally observed that the model $\mathrm{M}=8$ covers $\{(309659.39951-27608.77251) / 309659.39951\}=91 \%$ of all observations.

When a multivariate model with a smaller $\mathrm{M}$ and with the lowest degree of freedom has a satisfactory fit, it is accepted because it gives a better explanation of the interaction between the rows and columns models. Therefore, we will prefer the multivariate model $\mathrm{M}=8$ which has a perfect fit.

\section{B. Evaluation of the Multivariate Model}

The practical implementation of multivariate statistics to a particular problem involve several types of univariate and multivariate analysis in order to understand the relationships between variables and their relevance to the actual problem being studied. In addition, multivariate statistics is concerned with multivariate probability distributions, in terms of both: how these can be used to represent the distributions of observed data; and how they can be used as part of statistical inference, particularly where several different quantities are of interest to the same analysis [13].

The expected frequencies under the independent and column effects models for the production of Aquaculture Fisheries products in EU26 are given below:

Note: The multivariate model RC $(M=8)$ seems to give much better fit, particularly at the end of nominal scale.

TABLE 13: EVALUATION OF THE MULTIVARIATE MODEL

\begin{tabular}{ccccc}
\hline Countries & Years & Data & $\begin{array}{c}\text { Values of } \\
\text { Model 0 }\end{array}$ & $\begin{array}{c}\text { Values Of } \\
\text { Rc(M=8) }\end{array}$ \\
\hline Row & Column & Data & $\begin{array}{c}\text { Observed } \\
\text { Model }\left(\mathrm{Fij}^{1}\right)\end{array}$ & $\begin{array}{c}\text { Expected } \\
\text { Model } \\
\left(\text { Fij }^{2}\right)\end{array}$ \\
\hline $\mathbf{1}$ & 1 & 95 & 153 & 80 \\
$\mathbf{1}$ & 2 & 85 & 86 & 106 \\
$\mathbf{1}$ & 3 & 85 & 180 & 98 \\
$\mathbf{1}$ & 4 & 160 & 98 & 141 \\
$\mathbf{1}$ & 5 & 187 & 96 & 172 \\
$\mathbf{1}$ & 6 & 183 & 95 & 195 \\
$\mathbf{1}$ & 7 & 183 & 88 & 166 \\
$\mathbf{1}$ & 8 & 126 & 93 & 146 \\
$\mathbf{1}$ & 9 & 74 & 90 & 75 \\
$\mathbf{1}$ & 10 & 41 & 87 & 39 \\
$\mathbf{1}$ & 11 & 13 & 88 & 15 \\
$\mathbf{1}$ & 12 & 13 & 90 & 11 \\
$\mathbf{2}$ & 1 & 473 & 600 & 462 \\
$\mathbf{2}$ & 2 & 544 & 339 & 556 \\
$\mathbf{2}$ & 3 & 425 & 707 & 437 \\
$\mathbf{2}$ & 4 & 778 & 386 & 733 \\
$\mathbf{2}$ & 5 & 365 & 378 & 421 \\
$\mathbf{2}$ & 6 & 294 & 375 & 269 \\
$\mathbf{2}$ & 7 & 231 & 344 & 234 \\
$\mathbf{2}$ & 8 & 447 & 363 & 452 \\
$\mathbf{2}$ & 9 & 249 & 355 & 252 \\
$\mathbf{2}$ & 10 & 315 & 341 & 305 \\
$\mathbf{2}$ & 11 & 326 & 347 & 301 \\
$\mathbf{2}$ & 12 & 443 & 354 & 469 \\
$\mathbf{3}$ & 1 & 1820 & 2835 & 1804 \\
$\mathbf{3}$ & 2 & 1756 & 1602 & 1776 \\
$\mathbf{3}$ & 3 & 1723 & 3337 & 1739 \\
$\mathbf{3}$ & 4 & 1877 & 1825 & 1839 \\
$\mathbf{3}$ & 5 & 1947 & 1786 & 1967 \\
$\mathbf{3}$ & 6 & 2009 & 1770 & 2004 \\
$\mathbf{3}$ & 7 & 1921 & 1625 & 1913 \\
$\mathbf{3}$ & 8 & 1967 & 1716 & 1982 \\
\hline & & & & \\
\hline
\end{tabular}

\begin{tabular}{|c|c|c|c|c|}
\hline 3 & 9 & 1938 & 1675 & 1941 \\
\hline 3 & 10 & 2045 & 1610 & 2037 \\
\hline 3 & 11 & 2043 & 1639 & 2026 \\
\hline 3 & 12 & 2045 & 1671 & 2063 \\
\hline 4 & 1 & 4192 & 5678 & 4230 \\
\hline 4 & 2 & 3970 & 3209 & 3923 \\
\hline 4 & 3 & 4237 & 6685 & 4201 \\
\hline 4 & 4 & 4267 & 3655 & 4343 \\
\hline 4 & 5 & 4361 & 3578 & 4340 \\
\hline 4 & 6 & 4157 & 3545 & 4154 \\
\hline 4 & 7 & 3203 & 3255 & 3224 \\
\hline 4 & 8 & 3777 & 3437 & 3741 \\
\hline 4 & 9 & 4281 & 3355 & 4275 \\
\hline 4 & 10 & 3901 & 3225 & 3917 \\
\hline 4 & 11 & 2791 & 3283 & 2826 \\
\hline 4 & 12 & 3117 & 3348 & 3081 \\
\hline 5 & 1 & 8324 & 8953 & 8327 \\
\hline 5 & 2 & 6543 & 5060 & 6541 \\
\hline 5 & 3 & 7302 & 10541 & 7294 \\
\hline 5 & 4 & 7957 & 5764 & 8018 \\
\hline 5 & 5 & 6589 & 5642 & 6462 \\
\hline 5 & 6 & 5341 & 5589 & 5412 \\
\hline 6 & 12 & 78 & 33 & 78 \\
\hline 7 & 1 & 3493 & 7603 & 3572 \\
\hline 7 & 2 & 3685 & 4297 & 3588 \\
\hline 7 & 3 & 4238 & 8951 & 4174 \\
\hline 7 & 4 & 4386 & 4895 & 4438 \\
\hline 7 & 5 & 5125 & 4791 & 5333 \\
\hline 7 & 6 & 6094 & 4746 & 5932 \\
\hline 7 & 7 & 6257 & 4359 & 6267 \\
\hline 7 & 8 & 6252 & 4602 & 6205 \\
\hline 7 & 9 & 5836 & 4492 & 5816 \\
\hline 7 & 10 & 6005 & 4318 & 6040 \\
\hline 7 & 11 & 5312 & 4396 & 5463 \\
\hline 7 & 12 & 5250 & 4483 & 5105 \\
\hline 8 & 1 & 3985 & 12828 & 3902 \\
\hline 8 & 2 & 4884 & 7250 & 4991 \\
\hline 8 & 3 & 5993 & 15103 & 6064 \\
\hline 8 & 4 & 8427 & 8258 & 8351 \\
\hline 8 & 5 & 9542 & 8083 & 9376 \\
\hline 8 & 6 & 9751 & 8008 & 9882 \\
\hline 8 & 7 & 8793 & 7355 & 8751 \\
\hline 8 & 8 & 10143 & 7764 & 10216 \\
\hline 8 & 9 & 9714 & 7579 & 9730 \\
\hline 8 & 10 & 10627 & 7286 & 10599 \\
\hline 8 & 11 & 11317 & 7417 & 11221 \\
\hline 8 & 12 & 11319 & 7564 & 11411 \\
\hline 9 & 1 & 23163 & 40956 & 23199 \\
\hline 9 & 2 & 23917 & 23146 & 23856 \\
\hline 9 & 3 & 31370 & 48218 & 31341 \\
\hline 9 & 4 & 31819 & 26365 & 31795 \\
\hline 9 & 5 & 30904 & 25808 & 31100 \\
\hline 9 & 6 & 30892 & 25567 & 30780 \\
\hline 9 & 7 & 25473 & 23480 & 25555 \\
\hline 9 & 8 & 26820 & 24788 & 26744 \\
\hline 9 & 9 & 29332 & 24197 & 29332 \\
\hline 9 & 10 & 21937 & 23262 & 21922 \\
\hline 9 & 11 & 29489 & 23680 & 29420 \\
\hline 9 & 12 & 28498 & 24148 & 28571 \\
\hline 10 & 1 & 28553 & 37790 & 28460 \\
\hline 10 & 2 & 28724 & 21356 & 28850 \\
\hline 10 & 3 & 26785 & 44490 & 26857 \\
\hline 10 & 4 & 26486 & 24327 & 26490 \\
\hline 10 & 5 & 26680 & 23812 & 26292 \\
\hline 10 & 6 & 25166 & 23590 & 25428 \\
\hline 10 & 7 & 25177 & 21665 & 25119 \\
\hline 10 & 8 & 23962 & 22872 & 24049 \\
\hline 10 & 9 & 24267 & 22326 & 24285 \\
\hline 10 & 10 & 24516 & 21464 & 24497 \\
\hline 10 & 11 & 23761 & 21849 & 23663 \\
\hline 10 & 12 & 23745 & 22281 & 23833 \\
\hline 11 & 1 & 18937 & 27856 & 18978 \\
\hline 11 & 2 & 19572 & 15742 & 19515 \\
\hline 11 & 3 & 20863 & 32794 & 20826 \\
\hline 11 & 4 & 21037 & 17932 & 21084 \\
\hline 11 & 5 & 21653 & 17553 & 21709 \\
\hline 11 & 6 & 21833 & 17389 & 21789 \\
\hline 11 & 7 & 18429 & 15970 & 18474 \\
\hline 11 & 8 & 19188 & 16859 & 19134 \\
\hline 11 & 9 & 11822 & 16457 & 11817 \\
\hline
\end{tabular}




\begin{tabular}{|c|c|c|c|c|}
\hline 11 & 10 & 18110 & 15821 & 18117 \\
\hline 11 & 11 & 17358 & 16105 & 17359 \\
\hline 11 & 12 & 18099 & 16423 & 18099 \\
\hline 12 & 1 & 79 & 285 & 77 \\
\hline 12 & 2 & 97 & 161 & 99 \\
\hline 12 & 3 & 118 & 335 & 119 \\
\hline 12 & 4 & 142 & 183 & 144 \\
\hline 12 & 5 & 188 & 179 & 175 \\
\hline 12 & 6 & 188 & 178 & 198 \\
\hline 12 & 7 & 186 & 163 & 189 \\
\hline 12 & 8 & 182 & 172 & 181 \\
\hline 12 & 9 & 218 & 168 & 219 \\
\hline 12 & 10 & 239 & 162 & 237 \\
\hline 12 & 11 & 361 & 165 & 351 \\
\hline 12 & 12 & 320 & 168 & 330 \\
\hline 13 & 1 & 38 & 72 & 40 \\
\hline 13 & 2 & 35 & 41 & 33 \\
\hline 13 & 3 & 43 & 85 & 42 \\
\hline 13 & 4 & 47 & 46 & 46 \\
\hline 13 & 5 & 33 & 45 & 43 \\
\hline 13 & 6 & 46 & 45 & 40 \\
\hline 13 & 7 & 43 & 41 & 44 \\
\hline 13 & 8 & 64 & 44 & 63 \\
\hline 13 & 9 & 55 & 43 & 55 \\
\hline 13 & 10 & 54 & 41 & 54 \\
\hline 13 & 11 & 57 & 42 & 60 \\
\hline 13 & 12 & 73 & 43 & 70 \\
\hline 14 & 1 & 154 & 303 & 164 \\
\hline 14 & 2 & 152 & 171 & 142 \\
\hline 14 & 3 & 152 & 356 & 143 \\
\hline 14 & 4 & 165 & 195 & 187 \\
\hline 14 & 5 & 200 & 191 & 195 \\
\hline 14 & 6 & 200 & 189 & 195 \\
\hline 14 & 7 & 175 & 174 & 165 \\
\hline 14 & 8 & 236 & 183 & 238 \\
\hline 14 & 9 & 270 & 179 & 266 \\
\hline 14 & 10 & 201 & 172 & 211 \\
\hline 14 & 11 & 223 & 175 & 262 \\
\hline 14 & 12 & 338 & 178 & 299 \\
\hline 15 & 1 & 808 & 1792 & 807 \\
\hline 15 & 2 & 933 & 1013 & 939 \\
\hline 15 & 3 & 1022 & 2110 & 1024 \\
\hline 15 & 4 & 1195 & 1154 & 1198 \\
\hline 15 & 5 & 1289 & 1129 & 1281 \\
\hline 15 & 6 & 1306 & 1119 & 1305 \\
\hline 15 & 7 & 1157 & 1027 & 1133 \\
\hline 15 & 8 & 1187 & 1085 & 1205 \\
\hline 15 & 9 & 1274 & 1059 & 1271 \\
\hline 15 & 10 & 1366 & 1018 & 1374 \\
\hline 15 & 11 & 1469 & 1036 & 1511 \\
\hline 15 & 12 & 1592 & 1057 & 1550 \\
\hline 16 & 1 & 155 & 364 & 154 \\
\hline 16 & 2 & 180 & 206 & 184 \\
\hline 16 & 3 & 195 & 429 & 195 \\
\hline 16 & 4 & 200 & 234 & 210 \\
\hline 16 & 5 & 175 & 230 & 153 \\
\hline 16 & 6 & 124 & 227 & 133 \\
\hline 16 & 7 & 112 & 209 & 94 \\
\hline 16 & 8 & 89 & 220 & 102 \\
\hline 16 & 9 & 87 & 215 & 85 \\
\hline 16 & 10 & 74 & 207 & 81 \\
\hline 16 & 11 & 717 & 211 & 747 \\
\hline 16 & 12 & 859 & 215 & 828 \\
\hline 17 & 1 & 9987 & 11365 & 10017 \\
\hline 17 & 2 & 9821 & 6423 & 9784 \\
\hline 17 & 3 & 12010 & 13380 & 11987 \\
\hline 17 & 4 & 10876 & 7316 & 10885 \\
\hline 17 & 5 & 7523 & 7161 & 7626 \\
\hline 17 & 6 & 5704 & 7094 & 5629 \\
\hline 17 & 7 & 5443 & 6515 & 5447 \\
\hline 17 & 8 & 6654 & 6878 & 6637 \\
\hline 17 & 9 & 7860 & 6714 & 7852 \\
\hline 17 & 10 & 7137 & 6455 & 7149 \\
\hline 17 & 11 & 4220 & 6571 & 4278 \\
\hline 17 & 12 & 5337 & 6701 & 5281 \\
\hline 18 & 1 & 295 & 386 & 288 \\
\hline 18 & 2 & 302 & 218 & 311 \\
\hline 18 & 3 & 291 & 455 & 297 \\
\hline 18 & 4 & 307 & 249 & 300 \\
\hline 18 & 5 & 285 & 244 & 273 \\
\hline
\end{tabular}

\begin{tabular}{|c|c|c|c|c|}
\hline 18 & 6 & 239 & 241 & 248 \\
\hline 18 & 7 & 233 & 222 & 228 \\
\hline 18 & 8 & 223 & 234 & 230 \\
\hline 18 & 9 & 227 & 228 & 228 \\
\hline 18 & 10 & 242 & 220 & 240 \\
\hline 18 & 11 & 250 & 223 & 244 \\
\hline 18 & 12 & 254 & 228 & 259 \\
\hline 19 & 1 & 2770 & 4973 & 2755 \\
\hline 19 & 2 & 2868 & 2811 & 2887 \\
\hline 19 & 3 & 2979 & 5855 & 2992 \\
\hline 19 & 4 & 3371 & 3201 & 3357 \\
\hline 19 & 5 & 3580 & 3134 & 3550 \\
\hline 19 & 6 & 3546 & 3105 & 3570 \\
\hline 19 & 7 & 3271 & 2851 & 3267 \\
\hline 19 & 8 & 3544 & 3010 & 3555 \\
\hline 19 & 9 & 3513 & 2938 & 3516 \\
\hline 19 & 10 & 3792 & 2825 & 3786 \\
\hline 19 & 11 & 3587 & 2875 & 3563 \\
\hline 19 & 12 & 3689 & 2932 & 3712 \\
\hline 20 & 1 & 536 & 1071 & 583 \\
\hline 20 & 2 & 719 & 605 & 656 \\
\hline 20 & 3 & 754 & 1260 & 710 \\
\hline 20 & 4 & 627 & 689 & 706 \\
\hline 20 & 5 & 754 & 675 & 762 \\
\hline 20 & 6 & 821 & 668 & 800 \\
\hline 20 & 7 & 829 & 614 & 870 \\
\hline 20 & 8 & 803 & 648 & 748 \\
\hline 20 & 9 & 670 & 632 & 664 \\
\hline 20 & 10 & 670 & 608 & 684 \\
\hline 20 & 11 & 790 & 619 & 809 \\
\hline 20 & 12 & 747 & 631 & 728 \\
\hline 21 & 1 & 1390 & 1441 & 1400 \\
\hline 21 & 2 & 1117 & 814 & 1109 \\
\hline 21 & 3 & 961 & 1696 & 954 \\
\hline 21 & 4 & 900 & 927 & 910 \\
\hline 21 & 5 & 973 & 908 & 996 \\
\hline 21 & 6 & 1082 & 899 & 1057 \\
\hline 21 & 7 & 925 & 826 & 901 \\
\hline 21 & 8 & 904 & 872 & 916 \\
\hline 21 & 9 & 814 & 851 & 808 \\
\hline 21 & 10 & 728 & 818 & 741 \\
\hline 21 & 11 & 911 & 833 & 976 \\
\hline 21 & 12 & 1031 & 849 & 967 \\
\hline 22 & 1 & 87 & 180 & 85 \\
\hline 22 & 2 & 92 & 102 & 95 \\
\hline 22 & 3 & 91 & 211 & 93 \\
\hline 22 & 4 & 121 & 116 & 115 \\
\hline 22 & 5 & 118 & 113 & 123 \\
\hline 22 & 6 & 126 & 112 & 124 \\
\hline 22 & 7 & 129 & 103 & 127 \\
\hline 22 & 8 & 135 & 109 & 137 \\
\hline 22 & 9 & 157 & 106 & 157 \\
\hline 22 & 10 & 135 & 102 & 134 \\
\hline 22 & 11 & 137 & 104 & 136 \\
\hline 22 & 12 & 135 & 106 & 136 \\
\hline 23 & 1 & 95 & 146 & 97 \\
\hline 23 & 2 & 125 & 83 & 121 \\
\hline 23 & 3 & 65 & 172 & 63 \\
\hline 23 & 4 & 87 & 94 & 88 \\
\hline 23 & 5 & 89 & 92 & 96 \\
\hline 23 & 6 & 100 & 91 & 96 \\
\hline 23 & 7 & 83 & 84 & 88 \\
\hline 23 & 8 & 88 & 89 & 83 \\
\hline 23 & 9 & 118 & 86 & 118 \\
\hline 23 & 10 & 96 & 83 & 96 \\
\hline 23 & 11 & 126 & 85 & 123 \\
\hline 23 & 12 & 120 & 86 & 123 \\
\hline 24 & 1 & 1766 & 2179 & 1731 \\
\hline 24 & 2 & 1643 & 1231 & 1693 \\
\hline 24 & 3 & 1602 & 2565 & 1636 \\
\hline 24 & 4 & 1545 & 1403 & 1478 \\
\hline 24 & 5 & 1540 & 1373 & 1555 \\
\hline 24 & 6 & 1574 & 1360 & 1572 \\
\hline 24 & 7 & 1513 & 1249 & 1464 \\
\hline 24 & 8 & 1256 & 1319 & 1311 \\
\hline 24 & 9 & 1282 & 1287 & 1284 \\
\hline 24 & 10 & 1436 & 1238 & 1431 \\
\hline 24 & 11 & 1289 & 1260 & 1310 \\
\hline 24 & 12 & 1303 & 1285 & 1283 \\
\hline 25 & 1 & 824 & 917 & 816 \\
\hline
\end{tabular}




\begin{tabular}{ccccc}
\hline $\mathbf{2 5}$ & 2 & 668 & 518 & 665 \\
$\mathbf{2 5}$ & 3 & 548 & 1080 & 558 \\
$\mathbf{2 5}$ & 4 & 600 & 590 & 534 \\
$\mathbf{2 5}$ & 5 & 483 & 578 & 595 \\
$\mathbf{2 5}$ & 6 & 677 & 573 & 630 \\
$\mathbf{2 5}$ & 7 & 562 & 526 & 613 \\
$\mathbf{2 5}$ & 8 & 633 & 555 & 602 \\
$\mathbf{2 5}$ & 9 & 599 & 542 & 607 \\
$\mathbf{2 5}$ & 10 & 588 & 521 & 561 \\
$\mathbf{2 5}$ & 11 & 755 & 530 & 650 \\
$\mathbf{2 5}$ & 12 & 534 & 541 & 641 \\
$\mathbf{2 6}$ & 1 & 109901 & 51165 & 109888 \\
$\mathbf{2 6}$ & 2 & 12972 & 28915 & 12989 \\
$\mathbf{2 6}$ & 3 & 137421 & 60236 & 137433 \\
$\mathbf{2 6}$ & 4 & 15480 & 32937 & 15465 \\
$\mathbf{2 6}$ & 5 & 15249 & 32240 & 15229 \\
$\mathbf{2 6}$ & 6 & 17051 & 31940 & 17068 \\
$\mathbf{2 6}$ & 7 & 17904 & 29333 & 17896 \\
$\mathbf{2 6}$ & 8 & 18184 & 30966 & 18197 \\
$\mathbf{2 6}$ & 9 & 20720 & 30228 & 20722 \\
$\mathbf{2 6}$ & 10 & 17281 & 29060 & 17277 \\
$\mathbf{2 6}$ & 11 & 17185 & 29582 & 17173 \\
$\mathbf{2 6}$ & 12 & 17420 & 30166 & 17431 \\
\hline
\end{tabular}

$\mathrm{F}_{\mathrm{ij}}{ }^{1}$ : Expected frequencies of the independence model.

$\mathrm{F}_{\mathrm{ij}}{ }^{2}$ : Expected frequencies of the multivariate model $\mathrm{M}=8$.

From Table 13 above, it is evident that the prices (value) of the model RC $(\mathrm{M}=8)$ fully fitted to the data.

\section{LOGARITHMS OF THE ROW COLUMN-EFFECTS ASSOCIATION MODEL - RC $(\mathrm{M}=8)$}

TABLE 14: RC (M=8) FROM THE RCDIM (ROW TAU-S)

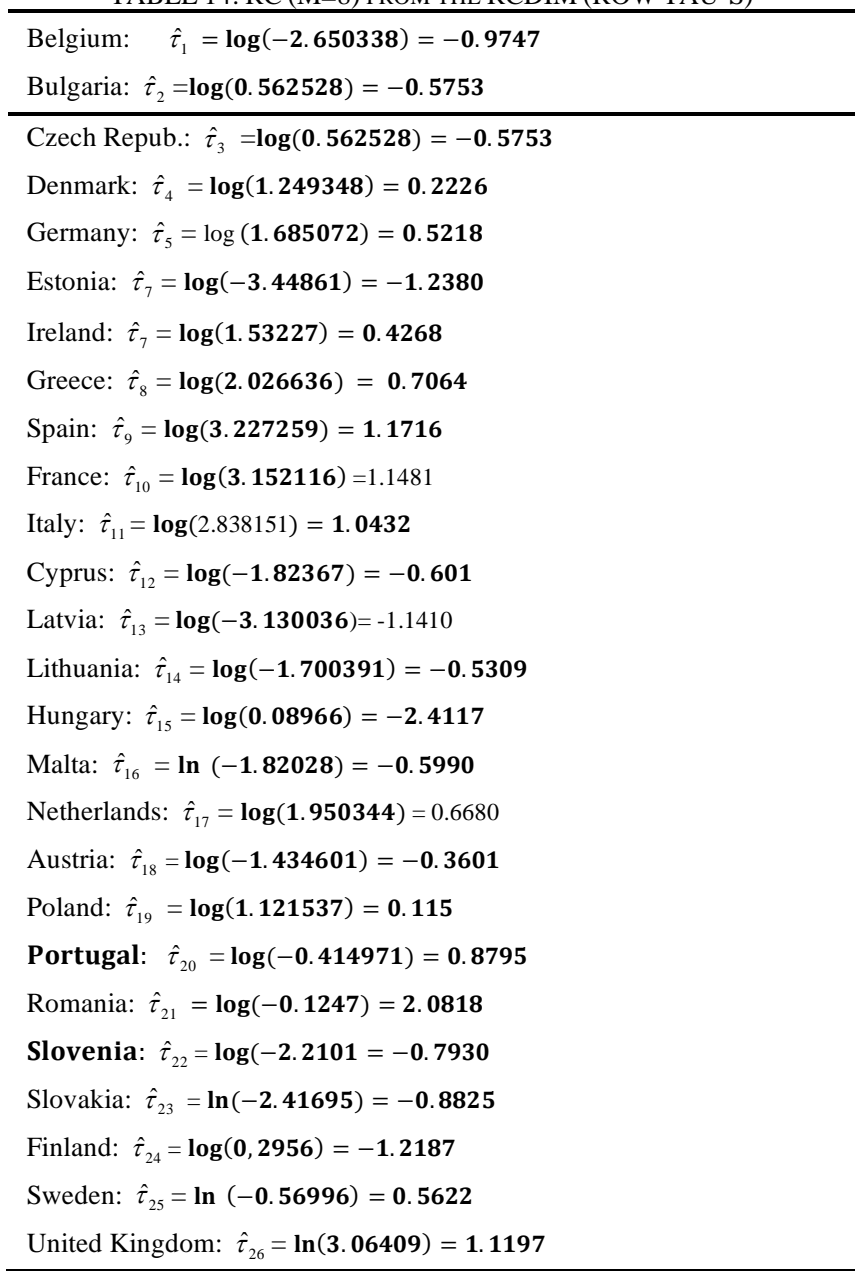

\section{RESEARCH FINDINGS \& COMPARISON OF THE FISHERIES AND AQUACULTURE PRODUCTS IN EU26}

Based on the logarithms of the Row Column-effects Association Model - RC (M=8) in Table 14 above, we compared some of the countries in the EU26 to ascertain the variation in production within the aquaculture fishery products from 2006-2017. The differences were observed: If we want to compare 2 countries then we get the difference of effects. For example:

When compared Greece and France, we realised that: $\hat{\tau}_{8}$ $\hat{\tau}_{10}=0.7064-1.1481=-0.4417$, $\exp (-0.4417)=0.6429$. It means that Greece has 0.6429 lesser tons of fishery products than France.

We compared Sweden with Poland: $\hat{\tau}_{25}-\hat{\tau}_{19}=0.5622$ $0.115=0.4472$, and $\exp (0.4472)=1.5639$. In other words, Sweden has 1.5639 tons of fishing products in aquaculture higher than that of Poland.

Comparing two Mediterranean countries like Spain and Italy, we find that: $\hat{\tau}_{9}-\hat{\tau}_{11}=1.1716-1.0432=0.0235$, $\exp (0.0235)=1.02379$. This means that Spain has 1.02379 tons of fishing products in aquaculture more than Italy.

The comparison of Denmark with Ireland was: $\hat{\tau}_{4}-\hat{\tau}_{7}=$ $0.2226-0.4268=-0.2042$, exp $(0.2042)=0.8153$. The difference between the two countries shows that Denmark has 0.8153 tons below the fishery products in Ireland.

By comparing Romania and Portugal, we have: Romania: $\hat{\tau}_{21}-\hat{\tau}_{20}=2.0818-0.8795=1.2023, \exp (1.2023)=3.3278$. The difference has a remarkable significance because Romania's production of fishery products is much more with 3.3278 tons in contrast with Portugal.

In the case of France and Germany we have: $\hat{\tau}_{10}-\hat{\tau}_{5}=$ $1.1481-0.5218=0.6218$, $\exp (0.6218)=1.8707$. From our observation, we could say that France has 1.8707 tons of production of fishery products than that of Germany.

Finally, the contrast between United Kingdom and Netherlands are: $\hat{\tau}_{26}-\hat{\tau}_{17}=1.1197-0.6680=0.4517$. $\exp (0.4517)=1.5710$. As it could be observed, the United Kingdom has 1.5710 tons of production of fishery products more than the Netherlands.

As shown in Table 15, ten EU Member States and Norway in 2017, reported first-sales data for 11 commodity groups. First-sales value increased over the previous year (2016) for Italy and Latvia. An opposite trend was experienced in Belgium, Denmark, Estonia, Norway, Portugal, Sweden, and the UK. First-sales value remained stable for France. Belgium's first sales decreased in both value $(-3 \%)$ and volume $(-5 \%)$ in 2016 . The main factors in the decrease were the drop in first-sales values and volumes for cod $(-19 \%$ in value, $-18 \%$ in volume), red mullet $(-35 \%$ in both value and volume), and sole $(-14 \%$ in value, $-11 \%$ in volume). The decrease observed during the first eight months of the year ended with the sharp increase in value and volume $(+33 \%$ and $+22 \%$, respectively) registered in September 2017 compared with September 2016. Of the main species, leading contributors to the increase in firstsales were sole $(+40 \%$ in value, $+43 \%$ in volume) and plaice ( $+32 \%$ in value, $17 \%$ in volume). 
TABLE 15: FIRST-SALES OVERVIEW OF 11 EU COUNTRIES (VOLUME IN TONS AND VALUE IN MILLION EUR) [5]

\begin{tabular}{|c|c|c|c|c|c|c|c|c|}
\hline \multirow[t]{2}{*}{ Country } & \multicolumn{2}{|c|}{$\begin{array}{c}\text { January-September } \\
2015\end{array}$} & \multicolumn{2}{|c|}{$\begin{array}{c}\text { January-September } \\
2015\end{array}$} & \multicolumn{2}{|c|}{$\begin{array}{c}\text { January-September } \\
2015\end{array}$} & \multicolumn{2}{|c|}{$\begin{array}{c}\text { Change from } \\
\text { January-September } \\
2016\end{array}$} \\
\hline & Volume & Value & Volume & Value & Volume & Value & Volume & Value \\
\hline Belgium & 12.671 & 48.50 & 12.192 & 47.55 & 11.576 & 46.33 & $-5 \%$ & $-3 \%$ \\
\hline Denmark & 193.409 & 229.64 & 179.170 & 263.64 & 183.943 & 249.60 & $3 \%$ & $-5 \%$ \\
\hline Estonia & 38.042 & 8.61 & 33.958 & 8.12 & 33.292 & 7.84 & $-2 \%$ & $-4 \%$ \\
\hline France & 147.072 & 486.12 & 144.096 & 482.57 & 142.767 & 484.32 & $-1 \%$ & $0 \%$ \\
\hline Italy & 65.620 & 240.70 & 63.480 & 238.87 & 66.113 & 246.94 & $4 \%$ & $3 \%$ \\
\hline Latvia & 37.024 & 9.17 & 36.280 & 7.83 & 41.705 & 8.47 & $15 \%$ & $8 \%$ \\
\hline Norway & 2.127 .510 & 1.560 .64 & 1.935 .845 & 1.622 .97 & 2.047 .402 & 1.567 .18 & $6 \%$ & $-3 \%$ \\
\hline Portugal & 86.591 & 145.40 & 78.590 & 151.08 & 74.034 & 148.63 & $-6 \%$ & $-2 \%$ \\
\hline Spain & 340.396 & 832.43 & 384.751 & 965.01 & 456.177 & 900.21 & $-7 \%$ & $-7 \%$ \\
\hline Sweden & 131.366 & 74.61 & 84.692 & 65.86 & 63.251 & 50.44 & $-25 \%$ & $-23 \%$ \\
\hline UK & 291.407 & 523.88 & 318.109 & 579.67 & 228.030 & 415.23 & $-28 \%$ & $-28 \%$ \\
\hline
\end{tabular}

Source: [5], volume data is reported in net weight.

The greatest increase in average prices was observed for cod and brill (both $+14 \%$ ). In 2017 Denmark's, first-sales value was EUR 250 million, a 5\% decrease in 2016; volume increased $3 \%$ at 184.000 tonnes. Lower prices of herring $(-16 \%), \operatorname{cod}(-3 \%)$, and plaice $(-9 \%)$ contributed to the decrease in value, whereas the larger landings of herring $(+10 \%$ at 95.780 tonnes $)$ increased overall volume. The decrease in first-sales value $(-3 \%)$ in 2016 was caused by herring, cod, Norway lobster, and plaice. Higher first-sales volume of mussel Mytilus spp. $(+160 \%)$, saithe $(+17 \%)$, and hake $(+14 \%)$ contributed to the overall increase in volume $(+29 \%)$. Mussel volume increased significantly due to opening and closing of fishing areas in Denmark.

Estonia experienced decreases in both first-sales value and volume $(-4 \%$ and $-2 \%$, respectively) from the same period a year before. Sprat ( $-10 \%$ in value, $-6 \%$ in volume) and pikeperch $(-54 \%$ in both value and volume) were most responsible for the decreases. In 2017, the trend was reversed; first-sales value and volume increased significantly $(+158 \%$ and $+385 \%$, respectively), over 2016 . The increases were caused by significantly higher first-sales prices as well as larger landings of herring and sprat. In addition, volume increased because of European perch $(+27 \%)$. Except for European perch $(+12 \%)$, average prices of herring and sprat experienced an opposite trend, and both decreased $19 \%$.

In France, first sales remained stable: unchanged in value and $1 \%$ lower in volume, in 2016. In 2017, there was a minor rise in the average price $(+2 \%)$, the first sales increased in value $(+2 \%)$ but did not change in volume compared with 2016. The top four species, anchovy, albacore tuna, cuttlefish, and ling, recorded a significant increase in value $(+109 \%,+43 \%,+63 \%$, and $+25 \%$, respectively) and only cuttlefish among these four registered a rise in price, from 4,14 to 5,08 EUR/kg (+23\%). Among the top ten species, the largest increase in volume was noted for anchovy $(+212)$ due to fisheries seasonality, while the largest decreases were observed for sardine $(-24 \%)$ and mackerel and monk (both $-11 \%$ ).

In 2017, Italy's first sales increased in both value $(+3 \%)$ and volume $(+4 \%)$ over the same period in 2016. Anchovy, clam, deep-water rose shrimp, hake, swordfish, octopus, and red mullet altogether represented $49 \%$ and $57 \%$ of total firstsales value and volume, respectively. A positive trend could be observed in value $(+3 \%$ over 2016), whereas first-sales value decreased $(-17 \%)$. The three most important species in value in 2017 were clam, sardine, and deep-water rose shrimp, which registered increases in value $(+3 \%,+95 \%$, and $+23 \%$, respectively, over 2016) despite a significant fall in price $(-16 \%)$ for deep-water rose shrimp, from 6,77 $\mathrm{EUR} / \mathrm{kg}$ in 2016 to 5,70 EUR/kg in 2017.

Latvia experienced increases in first-sales value $(+8 \%)$ and volume $(+15 \%)$ in 2017 , over the year 2016. This was caused by higher first-sales prices of cod $(+44 \%)$, sprat $(+14 \%)$, and smelt $(+43 \%)$ as well as with larger landings of these species. In 2017, a greater volume of cod $(+25 \%)$, European flounder $(+24 \%)$, and sprat $(+53 \%)$ contributed to the overall increase in volume of $16 \%$ over 2016 . A drop in the first-sales price of herring and sprat $(-4 \%$ and $-9 \%$, respectively) did not affect an overall rise in first-sales value $(+11 \%)$ over 2016. Smelt experienced the largest drop in price $(-43 \%)$ at $0,12 \mathrm{EUR} / \mathrm{kg}$ in 2017.

In 2017, Norway's, first-sales value decreased $3 \%$, to EUR 1,6 billion, whereas volume moved in the opposite direction $(+6 \%)$, ending at 2 million tonnes, compared with 2016. This was caused mainly by a lower first-sales price of mackerel, herring, and saithe, but larger catches of these species. In 2017, a negative trend was observed, with lower first-sales value and volume $(-11 \%$ and $-7 \%$, respectively). This was owing mainly to a lower first-sales price of herring at $1 \mathrm{EUR} / \mathrm{kg}(-23 \%)$, and of saithe, at $0,70 \mathrm{EUR} / \mathrm{kg}(-13 \%)$. Lower first-sales volume for cod $(-16 \%)$, crab $(-29 \%)$, and herring $(-15 \%)$ contributed to the overall decrease in volume in 2016.

In 2017 , first sales of Portugal decreased in value $(-2 \%)$ and volume $(-6 \%)$, from the same period in 2016 . The decrease in first-sales prices $(-10 \%)$ of all species landed contributed to the overall drop in value mainly because of octopus, sardine, and horse mackerel $(-5 \%,-13 \%$, and $-7 \%$, respectively). In 2017, first sales decreased in value $(-28 \%)$ and volume $(-20 \%)$ from 2016 . This was mainly the result of lower prices and smaller catch of anchovy (EUR $-4,6$ million net decrease), as well as of octopus, mackerel, scabbard fish, and sole. Of the top species, the average price decreased for clam at 1,28 EUR/kg $(-44 \%)$ and increased for octopus at 7,50 EUR/kg from 4,42 EUR/kg (+70\%) in September 2016.

In Spain, first sales fell $7 \%$ in both value and volume in 2017 from the same period in 2016. The trend was negative owing mainly to the lower first-sales prices and smaller volume of hake ( $-2 \%$ and $-7 \%$, respectively), albacore tuna $(-14 \%,-24 \%$, respectively) and monk (both $-11 \%)$. In 
2017, the first-sales value (EUR 91 million) fell 8\%, and volume ended at 37.189 tonnes, a decrease of $6 \%$ in 2016. Higher prices of clam $(+43 \%)$ and mackerel $(+27 \%)$, among others, did not offset an overall decrease in value that was caused in major part by albacore tuna $(-12 \%)$, sardine $(-44 \%)$, and anchovy $(-50 \%)$. A $96 \%$ increase in volume of mackerel did not reverse the overall negative volume created by horse mackerel $(-7 \%)$, hake $(-17 \%)$, and sardine $(-56 \%)$. Average prices decreased the most for mackerel $(-35 \%)$, ending at $0,36 \mathrm{EUR} / \mathrm{kg}$ in 2017 . In Sweden, decreases in both value $(-23 \%)$ and volume $(-25 \%)$ in 2017, from the same period in 2016, was caused by cod, herring, sprat, and Norway lobster. In 2017, first sales value of cod $(-24 \%)$, Norway lobster $(-57 \%)$, and saithe $(-34 \%)$ contributed to the overall decrease in value, whereas herring $(+103 \%$ at 11.537 tonnes) was the main contributor to overall increase in volume in 2017 over the same month in 2016. The average price of herring decreased $17 \%$ and the average price of saithe registered one of the largest decreases among the major species, dropping $21 \%$ to 1,43 EUR/kg in 2017 from 1,82 EUR/kg in 2016.

In the UK, both first sales value and volume decreased $28 \%$, from the same period in 2016, at EUR 415 million and 228.030 tonnes. Lower first-sales prices and smaller volume of haddock, Norway lobster, mackerel, and scallop were the main cause of the decrease. In 2017, the decrease in firstsales value $(-14 \%)$ and volume $(-3 \%)$ was caused mainly by herring with lower value and volume $(-57 \%$ and $-27 \%$, respectively). Also, the overall average prices decreased for all species landed $(-5 \%)$, of which herring registered the largest average price decrease of 40\% (0,41 EUR/kg in 2017 compared with $0,69 \mathrm{EUR} / \mathrm{kg}$ in 2016)

\section{SUMMARY}

As a first attempt to tackle the stagnation of fisheries and aquaculture production in the EU, the Commission published a communication entitled 'A strategy for the sustainable development of European aquaculture'. The objectives of this strategy were:

1. Creating long-term secure employment, particularly in fisheries-dependent areas, and increasing employment in aquaculture by between 8000 and 10000 full-time job equivalents over the period 2014-2021.

2. Ensuring the availability to consumers of products that are healthy, safe and of good quality, as well as promoting high animal health and welfare standards.

3. Ensuring an environmentally sound industry.

However, the strategy did not achieve its objectives, particularly as regards increasing production and employment: neither the target of a $4 \%$ growth rate nor that of 8000 to 10000 new jobs were achieved.

The main problem for the aquaculture sector has been the lack of production growth, in contrast to the high growth rate observed on a global scale. The sector has, however, seen good progress in areas such as ensuring availability of quality products to the consumer and ensuring environmental sustainability. In addition to the traditional obstacles and constraints, European aquaculture has met with increased competition from production in third countries since 2002 and has had to face crises of governance and the effects of the economic crisis after 2007.

To build a strategy on sustainable development of European aquaculture, on the 8/4/2009, the Commission published its second communication on aquaculture, seeking to identify and address the causes of the stagnation of EU aquaculture production (EMFF 2014-2020). It aimed to ensure that the EU remains a key player in a strategic sector, increasing production and employment by implementing the following actions:

A. Promoting the competitiveness of EU aquaculture production through:

$>$ Research and technological development

$>$ Promoting spatial planning for aquaculture in order to tackle the problem of competition over space

$>$ Enabling the aquaculture business to cope with market demands

$>$ Promoting aquaculture development in its international dimension

B. Establishing conditions for sustainable growth of aquaculture through:

$>$ Ensuring compatibility between aquaculture and the environment

$>$ Shaping a high-performance aquatic animal farming industry

$>$ Ensuring consumer health protection and recognising the health benefits of aquatic food products

C. Improving the sector's image and governance through:

* Better implementation of EU legislation

* Reducing the administrative burden

* Ensuring proper stakeholder participation and the provision of appropriate information to the public

* Ensuring adequate monitoring of the aquaculture sector.

The strategic guidelines for the sustainable development of EU aquaculture includes that: Member States were advised to ensure effectively their own national targets, taking account of their relative starting positions, national circumstances and institutional arrangements. These guidelines addressed four priority areas:

- Simplifying administrative procedures and reducing licensing time for aquaculture farms

- Coordinated spatial planning to overcome the hindering effect of the lack of space

- Enhancing the competitiveness of EU aquaculture

- Promoting a level playing field.

Based on the EU regulation, Member States were to submit multiannual national strategic plans for the development of aquaculture activities on their territory for the period 2014-2020. The Commission encouraged the exchange of information and best practices among Member States through different workshops and meetings. Member States carried out a mid-term assessment of the implementation of their multiannual national strategic plans at the end of 2017, while final assessment reports are expected from national governments at the beginning of 2021 (www.europa.eu). 


\section{CONCLUSION}

All the six association models show bad fit. Therefore we proceeded to the multivariate model in which the row column-effects RC multivariate model of RC $((\mathrm{M}=8)$ is better than all because it covers $91 \%$ of the data, thus, giving the best fit among all. However, to be more precise, the production of aquaculture fishery products from 2006-2017 in EU26 could have been influenced by several factors; these could be as a result of:

- The standard of living of each country

- The degree of utilisation of the workforce, which is directly related to efficiency in the production of goods and services [17].

- Government intervention (the efforts of public officials to react to such monopoly [18].

- $\quad$ Third party distortions caused by monopoly activity, for instance, in a country with exchange controls, commodities may only be imported with an import licence [15].

- A country's geopolitical culture and

- Several other factors which are difficult to be determined in each country

We should mention that $\Theta$, which is 0.99862 , i.e. approximately equal to 1 , reveal that we have independence between the variables. To determine the degree of association (correlation) between these countries and years, we use the $\theta$ of the second model, (the uniform association model which stand for (U) for calculation. More specifically, the innate correlation index in log-linear form is equal to:

$$
\log \left(\mathrm{F}_{\mathrm{ij}}\right)=\lambda+\lambda_{\mathrm{A}(\mathrm{i})}+\lambda_{\mathrm{B}(\mathrm{j})}+\varphi \chi_{\mathrm{i}} \mathrm{y}_{\mathrm{j}}
$$

where $\varphi$ is a single parameter for interaction.

The parameter of interaction

$$
\begin{gathered}
\varphi=\log \theta=\log (0.99862) \\
\Phi=\log (0.99862)=-0.001381 \\
|\varphi 1 / 2|=\sqrt{ } 0.001381=0.037161808 \\
\varphi 1 / 2=-\sqrt{ } 0.001381=-0.037161808
\end{gathered}
$$

In August 2017, household consumption of fresh fisheries and aquaculture products increased over August 2016 in both volume and value in Germany $(+26 \%$ and $+25 \%$, respectively), France (both $+2 \%)$, Ireland $(+2 \%$ and $+5 \%)$, Italy $(+3 \%$ and $+5 \%)$, the Netherlands $(+7 \%$ and $5 \%)$, and Sweden $(+24 \%$ and $+28 \%)$. Decreases in consumption in both volume and value were observed in Poland $(-19 \%$ and $-15 \%$, respectively). In Hungary, Portugal, and Spain, volumes decreased, and value increased. In the UK, volume increased, and value decreased.

The largest increase in volume in August 2017 was observed in Germany and in value in Sweden, while the largest drop in both volume and value was registered in Poland. Compared with July 2017, among the Member States surveyed, the highest increase in value was registered in Sweden $(+56 \%)$, followed by Italy $(+22 \%)$. Volume decreased $12 \%$ in both Denmark and Spain, followed by
Ireland $(-10 \%)$.

Finally, based on the parameter of interaction on the fisheries and aquaculture products EU26, the result reveals that there is a slightly negative association (correlation) between the 26 countries of the European Union and the years under our study.

The general observation is that, facts and figures on EU aquaculture production and consumption in an EU and global context has shown that, whereas there was an increase in fisheries and aquaculture production globally between 2006 and 2017, the aggregated production of farmed seafood in all EU Member States remained stable for a long time at around 1.2 million tonnes. EU production figures have, however, increased recently by around $24 \%$, with the value of European aquaculture products in late 2017 reaching EUR 5.6 billion.

\section{ACKNOWLEDGMENT}

I would like to extend my special thanks to Dr Antonia Gkouma, resident doctor in Thoracic and Cardiac Surgery at Royal Brompton Hospital London, UK not only for the selection of this challenging and innovative theme that subsequently kept me beneficial from my numerous skill set, and allow me to incorporate the entirety of my strengths and abilities, contributing wholesomely to my continuing professional development (CPD), but also for the decisive support and encouragement to the completion of this research.

Together, I would like to thank my co-authors: Ezechukwu, Christiana Uzoma - Assistant Chief Superintendent, Agricultural Development Programme (ADP), Umuahia, Abia State Nigeria; Ohia, Adanma Ngozi - Senior Lecturer, University of Portharcourt, River state, Nigeria; Opara Peace - Confidential Secretary, Abia Secondary Education Management Board (SEMB), Umuahia, Abia State, Nigeria; Ezeji, Uchechi Mgbafor Principal 11, Amuzukwu Girls' Secondary School, Umuahia, Abia State Nigeria, and Uzokwe Chinwe Adaugo - Lecturer 1, Michael Okpara University of Agriculture Umudike, Umuahia, Abia State, Nigeria for their contributions and warm support for this time consuming and memorable experience.

Also, I would like to thank everyone who helped in one way or the other particularly, Mrs Angelina Nnaduo, Mrs Blessing Chinwe Nwaubani, Mrs Faith Chikodi Nnaduo, Miss Goodness Ihechiluru Nwaubani, Miss Blessing Chihurumnanya Ogbonna, Miss Irene Nnenna iroeche, Mrs Maureen Mgbechi Chikezie, Mrs Charity Nkemhuruanya Alozie, Mrs Magdalene Zelka Bozidis, Mrs Christina Patricia, Mrs Benetia Sirgoudi, Mr Chinonso Victor Nwoko, Mr Victor Obinna Iwundu and Mr. Stamatis Bozidis.

\section{REFERENCES}

[1] Food and Agriculture Organization of the United Nations (FAO) FAO Fisheries statistics, the FAO Fishery Information, Data and Statistics Unit 2016.

[2] World Bank, [2012]. World Bank, Food and Agriculture Organization, World Fish Centre 2012. The Hidden Harvests: The Global Contribution of Capture Fisheries - Conference Edition. Washington, D.C. 
[3] United Nations population estimates and projections prepared by the Population Division of the Department of Economic and Social Affairs of the United Nations Secretariat 2017.

[4] 2008-2020, www.countries-ofthe-world.com.

[5] European Market Observatory for fisheries and aquaculture (EUMOFA), FAO, national administrations and FEAP Data 2017/2016.

[6] Eliason P. Scott-Clifford Clogg (1990), Categorical Data Analysis (CDAS).

[7] Diewert, W. Erwin, (1976). Exact and Superlative Index Numbers,', Journal of econometrics May 1976, 4: 115-45.

[8] Goodman, L.A., (1979b), Multiple Models for the Analysis of Occupational Mobility Tables and Other Kinds of CrossClassification Tables. "American Journal of Sociology".

[9] Goodman, L.A., (1981a), Association models and the Bivariate Normal for Contingency Tables with Ordered Categories, Biometrica, 68:347-55.

[10] Clogg, C.C. (1990), Analysis of Association (ANOAS) Program.

[11] Schwarz, Gideon E. (1978), "Estimating the dimension of a model", Annals of Statistics, 6 (2): 461-464.

[12] Haritou A.., Nwaubani J C., (2008). "Categorical Data Analysis" Working paper (University Press).

[13] Haritou A.., Nwaubani J C., (2010). "Categorical Data Analysis" Working paper (University Press).

[14] Goodman, L.A., (1981b). Association Models and Canonical Correlation in the Analysis of Cross-Classifications Having Ordered Categories. "Journal of American Statistical Association", 76:3, 2034.

[15] Bhagwati, J. (1982), "Directly Unproductive Profit Seeking Activities", Journal of Political Economy, vol. 90, pp. 988-1002.

[16] Goodman, L.A., (1979a). Multiple Models for the Analysis of Occupational Mobility Tables \& Other Kinds of Cross-Classification Tables, "American Journal of Sociology", 84:804-819.

[17] Olson M., (1982). The Rise and Decline of Nations: Economic Growth, Economic Rigidities and Stagflation, New Haven: Yale University Press.

[18] Monroe, K.R., (1991). "The Theory of Rational Action: What is it? How Useful is it for Political Science", in W. Crotty (ed.). 